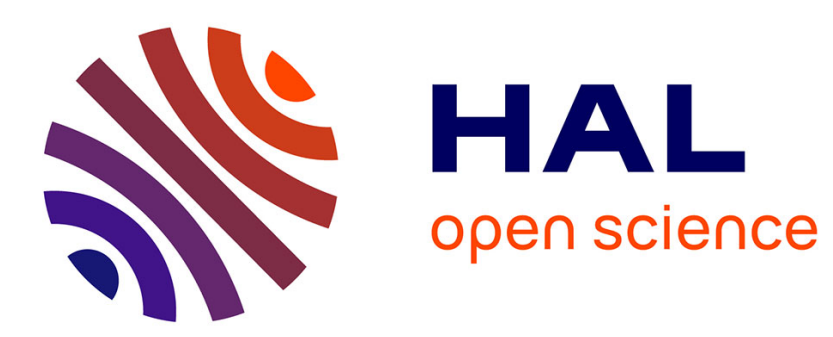

\title{
PLANAR DEFECTS IN PLASTICALLY DEFORMED SPINEL SINGLE CRYSTALS
}

\author{
P. Veyssiere, J. Rabier, H. Garem, J. Grilhé
}

\section{To cite this version:}

P. Veyssiere, J. Rabier, H. Garem, J. Grilhé. PLANAR DEFECTS IN PLASTICALLY DEFORMED SPINEL SINGLE CRYSTALS. Journal de Physique Colloques, 1976, 37 (C7), pp.C7-586-C7-589. 10.1051/jphyscol:19767136 . jpa-00216860

\section{HAL Id: jpa-00216860 https://hal.science/jpa-00216860}

Submitted on 1 Jan 1976

HAL is a multi-disciplinary open access archive for the deposit and dissemination of scientific research documents, whether they are published or not. The documents may come from teaching and research institutions in France or abroad, or from public or private research centers.
L'archive ouverte pluridisciplinaire HAL, est destinée au dépôt et à la diffusion de documents scientifiques de niveau recherche, publiés ou non, émanant des établissements d'enseignement et de recherche français ou étrangers, des laboratoires publics ou privés. 


\title{
PLANAR DEFECTS IN PLASTICALLY DEFORMED SPINEL SINGLE CRYSTALS
}

\author{
P. VEYSSIERE, J. RABIER, H. GAREM and J. GRILHE \\ Laboratoire de Métallurgie Physique, 40 avenue du Recteur Pineau \\ 86022 Poitiers, France
}

\begin{abstract}
Résumé. - Des défauts plans sont observés après déformation plastique de monocristaux de ferrite de nickel lorsque celle-ci s'accompagne de la production d'une seconde phase. Ces défauts sont situés dans la matrice spinelle et sont bordés par des dislocations partielles. Trois exemples sont étudiés, les plans de stabilisation comparés aux résultats de calculs antérieurs. La détermination de certains vecteurs de Burgers partiels est reliée au mécanisme de formation proposé de la seconde phase.
\end{abstract}

\begin{abstract}
Planar defects as observed when plastic deformation of nickel ferrite single crystals involves second phase production are studied. They lie within spinel matrix lamellae and are bounded by partial dislocations. Examples are studied, the determinations of displacement vectors and stabilization planes are compared with previous stacking fault energy calculations. From determination of partial Burgers vectors it seems possible that these defects could be related to partial dislocations involved in stress assisted second phase production.
\end{abstract}

1. Introduction. - As part of a comprehensive study of the mechanical properties of spinel ferrite single crystals we have previously characterized dislocation networks resulting from high temperature compressive tests and verified that dislocations generally have $a / 2<110>$ Burgers vector [1]. This paper is concerned with the study of secondary structural defects appearing as extended stacking faults in specimens deformed at temperatures still larger than $T_{\mathrm{M}} / 2$ but lower than the temperatures involved in [1]. Similar planar defects can also be easily created inside the microscope by electron beam heating (Fig. 1),

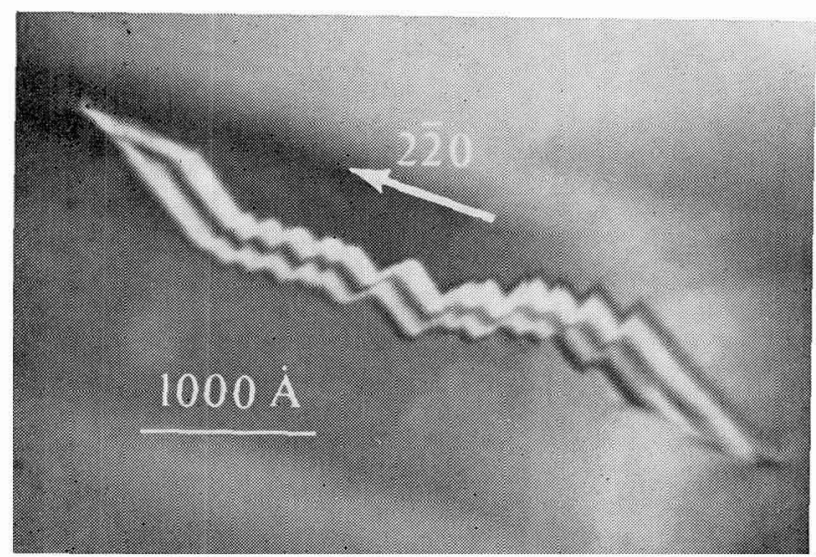

FIG. 1. - Folded stacking fault induced by mean heating.

however it is known that this treatment at least affects stoichiometry [2], they cannot be simply related to the original compound and will not be studied here.
2. Experimental. - The observations reported in this article were taken from nickel ferrite single crystals $\left(\mathrm{Ni}_{0.66} \mathrm{Fe}_{2.34} \mathrm{O}_{4}\right)$ deformed in compression along $\langle 100\rangle$ and $\langle 110\rangle\left(\varepsilon \sim 1.1 \times 10^{-5} \mathrm{~s}^{-1}\right)$. Each of them was deformed at decreasing temperatures from $1600^{\circ} \mathrm{C}$ to $1100^{\circ} \mathrm{C}$ of about $2 \%$. The lower test temperatures were limited by specimen fracture. Lines were directly observed on specimen faces without etch pitting [3] leading mainly to $\{111\}$ and $\{112\}$ planes. Thin foils suitable for observation were chemically polished as described previously [1].

3. Observations. - Planar defects were quite exclusively found near crystal slices inhomogeneously distributed in the matrix and appearing as second phase with hexagonal structure. Interfaces are often parallel to $\{111\}$. In order to explain twin formation Hornstra [4] has suggested a mechanism involving sweeping by partial dislocations with $a / 12<112>$ Burgers vector between successive oxygen planes, it is possible to interpret slices formation by a process completely analogous to Hornstra's model with same partials but sweeping each two oxygen planes. This selective shear can easily be justified by the different natures of cation layers and probably occurs in kagomé ones; however line analysis suggests other boundary orientations - mainly $\{112\}$ - for which the situation is less clear $\left({ }^{1}\right)$. Three different examples of stacking faults observed in the vicinity of second phase slices are given below, they always lie in the

(1) The study of these slices is in progress and will be published later. 
spinel matrix, they are throught to be representative of those which can be observed in deformed spinels.

3.1 Folded STACKing faults. - As illustrated by figure 1, stacking faults can show a stepped configuration, such geometries have been previously reported by Lewis in magnesium aluminium spinels [5], they are the most frequently observed ones. Only the simple example in figure 2 will be studied here : the fault is

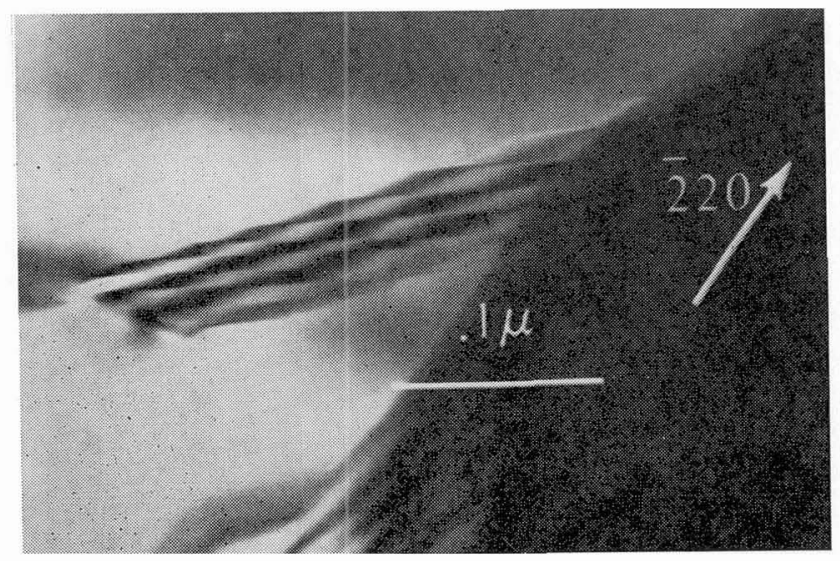

a)

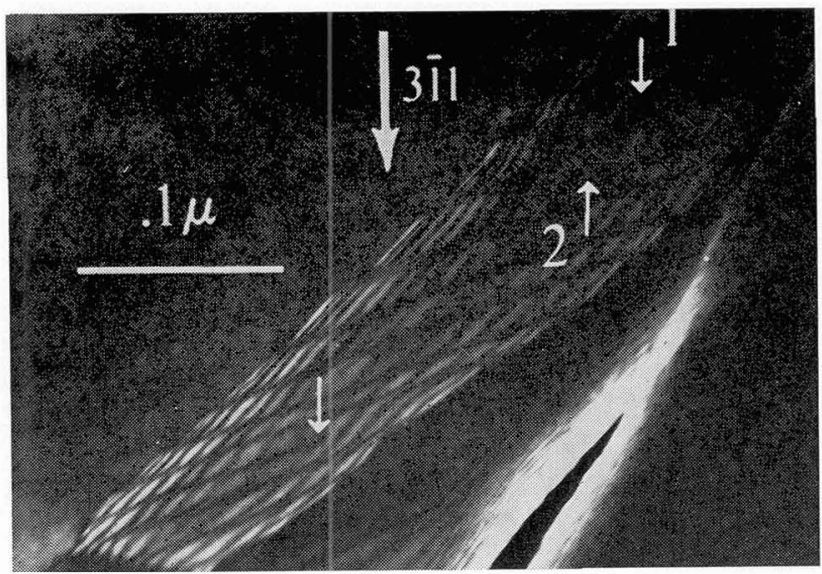

b)

FIG. 2. - Folded stacking fault in a deformed specimen, imaged under two different orientations.

limited by a straight dislocation and disappears under the interface between the spinel matrix and the slice. The geometrical properties of the whole defect are summarized in table $\mathrm{I}$. The displacement vector is

\section{TABLE I}

Characteristical features of the defect in figure 2

\begin{tabular}{|c|c|c|c|c|c|}
\hline \multicolumn{4}{|c|}{ Stacking fault } & \multicolumn{2}{|c|}{ Partial dislocation } \\
\hline $\mathbf{R}$ & LF & IF & edge & b & direction \\
\hline $\pm a / 4$ & - & & & $\pm \bar{a} / 4$ & \\
\hline [121] & (001) & (101) & [010] & [121] & [121] \\
\hline
\end{tabular}

$\mathbf{R}= \pm a / 4[121]$ or any vector deduced from it through a translation $a / 2<110>$ (for example : $\pm a / 4[\overline{101}]$ or $\pm a / 4[121])$. This very determination was chosen in conjunction with the bounding partial dislocation one whose Burgers vector may be in principle any of the preceeding ones : off all possible Burgers vectors only $\pm a / 4[121]$ (screw orientation) shows good consistency with the observed contrasts (15 different conditions of diffraction). Fault steps are alternately parallel to (001) (large ones, LF) and to (101) (inclined ones, IF), their intersection is parallel to [010]. The formation of this defect may be explained as follows : a dislocation with a/4 [121] Burgers vector - possibly involved in second phase production as zonal dislocation - has escaped from the interface into the spinel matrix leaving beside it a stacking fault in an unfavourable plane, the defect then stabilized into a stepped configuration where faults adopt orientations resulting in minimum energy for the whole defect : indeed it is not necessary that both two faults stabilize in planes with lowest energy [6] since this could result in surface and possibly energy increases. Four arguments can be given to substantiate this hypothesis : (i) only one fault plane is a glide plane for the partial, (ii) the dislocation line and step edges are not parallel, (iii) step discontinuities are observed (arrows in Fig. 2), for example arrows 1 and 2 indicate two segmented steps with complementary lengths as if fault folding had been nucleated in different areas of the initial planar defect, (iiii) the plane determined by the dislocation line and the average direction of the fault intersection with the surfaces is not a simple one whereas LF and IF have rather favourable stacking fault energies [6].

3.2 FAUltS WITH « STAIR-ROD 》 DISLOCATION. Contrary to the preceeding folded fault the defect presented in figure 3 shows a dislocation at the intersection of the two differently oriented fault planes. Due to the influence on general contrast of etch pits at dislocation emergence points, the displacement vector of the longest could only be determined : $\mathbf{R}=a / 12$ [112] which corresponds to a fault affecting both cation and anion sublattices. This configuration has also been observed once in other spinel compounds $\left({ }^{2}\right)$.

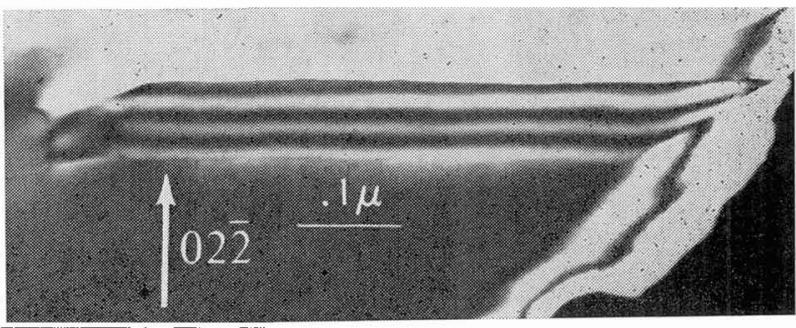

Fra. 3.

3.3 Planar multifaulted defects. - The configuration shown in figure 4 is composed of coplanar or

(2) Mishra, R. K., Thomas, G., private communication. 


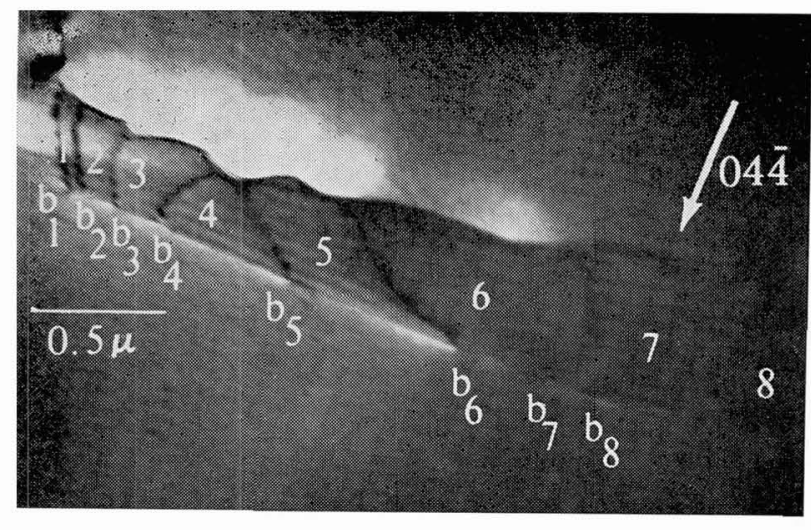

a)

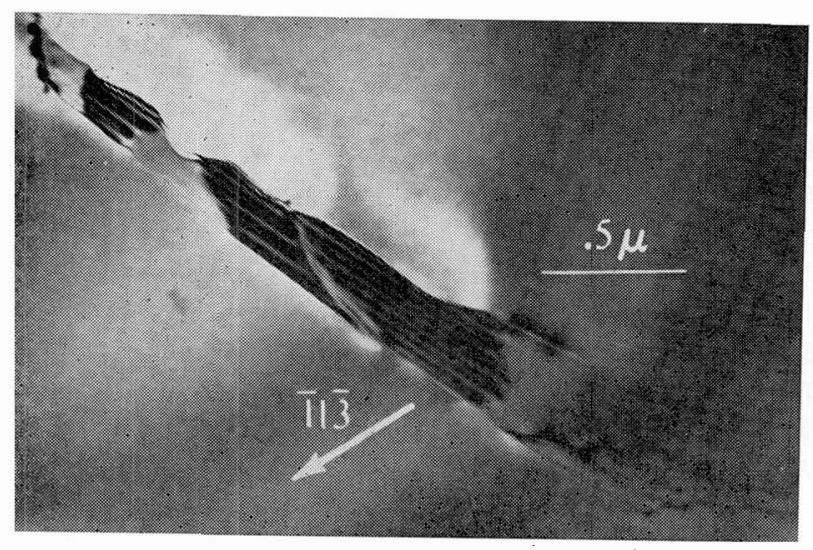

b)

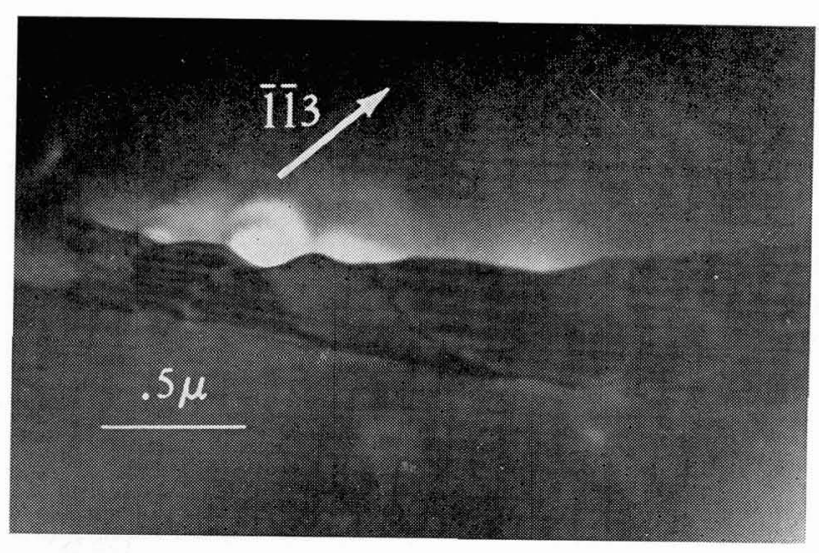

c)

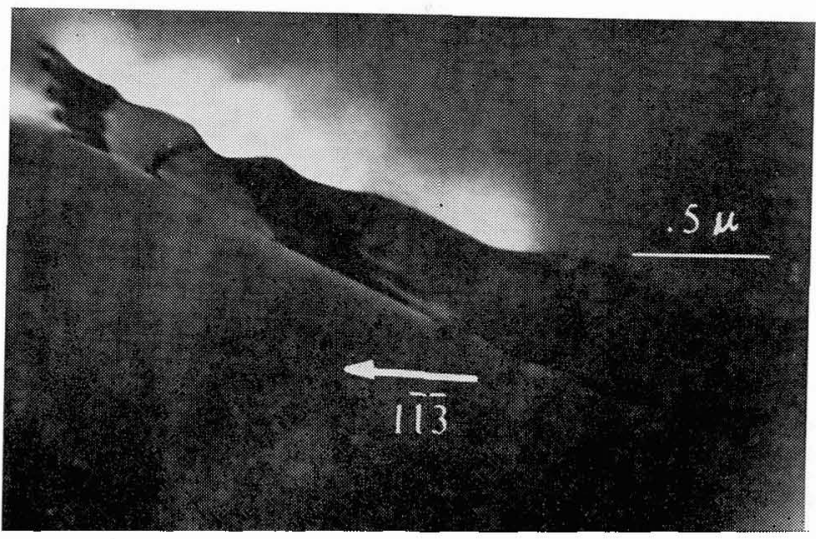

d)

FiG. 4. - Multi-faulted defect ; Fig. $4 a$ : notations ; Fig. $4 b, 4 c, 4 d$ : three different imaging conditions showing all faults with fringe contrast.

overlapping stacking faults separated by partial dislocations. Related notations are given in figure $4 a$, displacement and Burgers vectors in table II. All extended parts of the defect ( 1 to at least 8 , Fig. $4 a$ ) clearly show fringe contrast for different conditions of diffraction (Fig. $4 b, 4 c, 4 d$ ) i. e. none of them was found systematically out of contrast as classically observed in $f$. c. c. metals for example. The defect is parallel to (101), it must be noted that some of the partials cannot glide in this plane. Part of the indetermination associated with stacking fault contrast $-\mathrm{i}$. e. in spinels any $a / 4<110>$ displacement vector is equivalent to two different $a / 4<112>$ ones - has been eliminated since one must have $\mathbf{b}_{\mathbf{i}}=\mathbf{R}_{\mathbf{i}+1}-\mathbf{R}_{\mathbf{i}}$ where $\mathbf{R}_{\mathbf{i}+1}$ and $\mathbf{R}_{\mathbf{i}}$ are the observed displacement vectors. All displacement and Burgers vectors were determined independently and revealed satisfactorily consistent with each imaging condition $(21 \mathrm{~g})$ and with the above relation except $\mathbf{b}_{8}$ which, due to foil thickness, has been calculated using the relation only. No reasonable mechanism of this, defect formation has been found, however it is thought that it could correspond to a multifaulted loop section. Note that the presence of $a / 2<001>$ Burgers vectors can be explained by the association of two unresolved dislocations with $a / 4<110>$ perpendicular ones. At last, one can wonder in this example if the second phase is actually related to the defect since all partial Burgers are of $a / 4<110>$ or $a / 2<100>$ types.

\section{TABLE II}

Displacement and Burgers vectors corresponding to the defect in figure 4 (a/4 units). All vectors taken with opposite sens is also solution

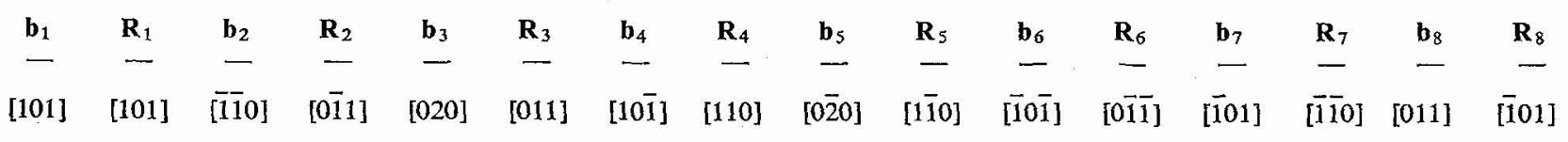


4. Conclusion. - Three extended faulted defects have been studied ; they are typical of those observed in deformed spinel single crystals (nickel ferrite). Two of them found near slices of stress assisted second phase with hexagonal structure substantiate the idea that this second phase is produced by a mechanism involving $a / 12<112\rangle$ isolated or grouped partials dislocations. These results are preliminary ones, a detailed study of the slice structure(s) as well as their relation(s) with the matrix and secondary extended defect production will be published later. Also in these examples climb participation to the defect formation could be evidenced.

\section{References}

[1] Veyssière, P., Rabier, J., Garem, H., Grilhe, J., Phil. Mag. 33 (1976) 143.

[2] Doukhan, N., Doukhan, J. C., Escaig, B., Mat. Res. Bull. 11 (1976) 125.

[3] Rabier, J., Veyssière, P., Grilhe, J., J. Mat. Sci. 11 (1976) 193.
[4] Hornstra, J., J. Phys. \& Chem. Solids 15 (1962) 311.

[5] Lewis, M. H., Phil. Mag. 17 (1968) 481.

[6] Veyssière, P., Rabier, J., Grilhe, J., Phys. Status Solidi 31 (1975) 605. 